\title{
One-step co-culture fermentation strategy to produce high-content fructo-oligosaccharides
}

\author{
C. Nobre*, D.A. Gonçalves, J.A. Teixeira, L.R. Rodrigues \\ CEB - Centre of Biological Engineering, University of Minho, 4710-057 Braga, Portugal
}

\section{A R T I C L E I N F O}

\section{Keywords:}

Fructo-oligosaccharides

Co-culture

Integrated process

Aspergillus ibericus

Saccharomyces cerevisiae

One-step fermentation

\begin{abstract}
A B S T R A C T
An integrated process enabling the simultaneous production and purification of fructo-oligosaccharides (FOS) was explored. A co-culture fermentation with Aspergillus ibericus (used as FOS producer strain) and Saccharomyces cerevisiae YIL162 W (for small saccharides removal) was optimized. Inoculation conditions of $S$. cerevisiae, fermentative broth composition, temperature and $\mathrm{pH}$ were optimized by experimental design. Yeast extract concentration and temperature were the most significant variables affecting FOS purity. Co-culture fermentations with simultaneously inoculation of the strains, run under $30^{\circ} \mathrm{C}$, initial $\mathrm{pH} 6.0$ and $17 \mathrm{~g} \mathrm{~L}^{-1}$ yeast extract led to FOS mixtures with $97.4 \pm 0.2 \%(\mathrm{w} / \mathrm{w})$ purity. The fermentations conducted in bioreactor, at a 0.8 vvm aeration rate, yielded $0.70 \pm 0.00 \mathrm{~g}_{\mathrm{FOS}} \cdot \mathrm{g}_{\text {initial } \mathrm{GF}^{-1}}$ at $45 \mathrm{~h}$ fermentation, with a FOS content of $133.7 \pm 0.1 \mathrm{~g} \mathrm{~L}^{-1}$. A purity of FOS up to $93.8 \pm 0.7 \%(\mathrm{w} / \mathrm{w})$ was achieved. The one-step fermentation proved to be efficient, economical and fast.
\end{abstract}

\section{Introduction}

Growing consumer awareness on high nutritional value ingredients and their impact in health has been raising the interest in functional food. Among functional food, fructo-oligosaccharides (FOS) are increasingly popular fulfilling all the criteria to be considered prebiotics (Nobre, Cerqueira, Rodrigues, Vicente, \& Teixeira, 2015). They are not hydrolyzed by the human digestive system but are completely fermented selectively by health-promoting colonic microbiota, bifidobacteria and lactobacilli (Nobre, Sousa et al., 2018), to short-chain fatty acids, inhibiting the growth of harmful microorganisms, and stimulating the immune system, reducing liver toxins, and aiding the absorption of certain minerals (Younis, Ahmad, \& Jahan, 2015).

FOS have been industrially produced via sucrose fermentation by several purified microorganism's enzymes, in a two-step bioprocess including 1) microorganism growth fermentation and enzyme production and 2) FOS synthesis with the purified enzymes. Microorganisms belonging to Aspergillus, Penicillium and Aureobasidium genera are the most reported for FOS production (Maiorano, Piccoli, Da Silva, \& De Andrade Rodrigues, 2008; Nascimento, Nobre, Cavalcanti, Teixeira, \& Porto, 2016). During the fermentation process, a high amount of glucose is generated, which induces enzyme activity inhibition, leading to low sucrose conversion yield $\left(0.55-0.60 \mathrm{~g}_{\mathrm{FOS}} \mathrm{g}_{\text {sucrose }}{ }^{-1}\right)$ and more than $10 \%$ of unreacted sucrose (Nishizawa, Nakajima, \& Nabetani, 2001;
Sangeetha, Ramesh, \& Prapulla, 2005). Consequently, FOS mixtures obtained at the end of the fermentation have only around $60 \%$ purity, thus preventing their inclusion in diabetic and dietetic food.

Numerous studies have been focused on the development of downstream treatments to purify FOS from sugar mixtures, such as the use of membrane techniques, chromatographic methods and microbial treatment using successive purification fermentations (Nobre, Teixeira, \& Rodrigues, 2012; Nobre, Suvarov, \& De Weireld, 2014; Nobre et al., 2016; Nobre, Teixeira, \& Rodrigues, 2015; Suvarov, Kienle, Nobre, De Weireld, \& Vande Wouwer, 2014; Yang, Wang, Teng, \& Zhang, 2008). Alternatively, FOS have been simultaneously produced and purified by mixtures of enzymes e.g. $\beta$-fructofuranosidase and glucose oxidase or by cell systems (Jung, Kim, Jeon, \& Lee, 1993; Sheu, Lio, Chen, Lin, \& Duan, 2001; Sheu, Duan, Cheng, Bi, \& Chen, 2002; Sheu, Chang, Wang, Wu, \& Huang, 2013; Yun \& Song, 1993). However, the use of free enzymes presents some practical limitations such as low stability, discontinuous production and limited reusability (Mouelhi, Abidi, \& Marzouki, 2016). These drawbacks make the whole-cell process a lot more appealing as it does not require enzyme purification from the microorganism cells and therefore, the fermentations are conducted in a one-step bioprocess. Production yields up to $0.64 \mathrm{~g}_{\mathrm{FOS}} \mathrm{g}_{\text {initial GF }}{ }^{-1}$ were achieved using whole-cells of Aspergillus ibericus (Nobre, Alves Filho et al., 2018) and Aureobasidium pullulans (Dominguez et al., 2012; Nobre et al., 2016).

\footnotetext{
* Corresponding author.

E-mail addresses: clarissenobre@deb.uminho.pt (C. Nobre), danielalexandra94@hotmail.com (D.A. Gonçalves), jateixeira@deb.uminho.pt (J.A. Teixeira), lrmr@deb.uminho.pt (L.R. Rodrigues).
} 
Our recent work, using a one-step process with a co-culture of $A$. pullulans with Saccharomyces cerevisiae clearly showed the potential of the yeast to reduce the glucose present in the broth. However, due to microorganisms' competition by the substrate, the fermentation yields obtained were slightly lower than the ones obtained using a single $A$. pullulans fermentation (Nobre et al., 2016). To overcome this effect, the use of a $S$. cerevisiae strain, with the gene responsible for sucrose hydrolysis disrupted, is herein proposed. FOS production and purification were optimized as an integrated process using whole-cells of both $A$. ibericus fungi for FOS production and $S$. cerevisae YIL162 W yeast for FOS purification. Co-culture conditions such as, initial yeast concentration, inoculation time, fermentative broth composition, temperature and $\mathrm{pH}$ were firstly optimized and finally, the process was scaled-up to a bioreactor.

\section{Material and methods}

\subsection{Microorganisms and culture conditions}

The fungus Aspergillus ibericus MUM 03.49 from Micoteca da Universidade do Minho (MUM) culture collection (Braga, Portugal) was used. The strain was revived in Czapeck Dox Agar (Oxoid, UK) plates from frozen glycerol stock solutions. After 7-day grown at $30^{\circ} \mathrm{C}$, spores were scrapped from the plates with a $0.1 \%(\mathrm{w} / \mathrm{v})$ solution of Tween 80 (Panreac, AppliChem, Spain) to prepare a concentrated spore suspension. The suspension spore concentration was determined using an improved Neubauer chamber, and afterwards adjusted to $1 \times 10^{8}$ spores. $\mathrm{mL}^{-1}$. The spores' solution was used to inoculate the shake-flask assays and the bioreactor inoculum.

$S$. cerevisiae strains used were acquired from EUROSCARF European $S$. cerevisiae archive for functional analysis. Both yeasts, $S$. cerevisiae BY4741 (wild type) and $S$. cerevisiae YIL162 W (with the gene responsible for sucrose hydrolysis disrupted (SUC2)), were grown in YPD (10 $\mathrm{g} \mathrm{L}^{-1}$ yeast extract, $20 \mathrm{~g} \mathrm{~L}^{-1}$ peptone, and $20 \mathrm{~g} \mathrm{~L}^{-1}$ glucose) agar plates for 7 days. Colonies were further transferred to a YPD liquid culture medium, previously autoclaved at $121^{\circ} \mathrm{C}$ for $15 \mathrm{~min}$, and grown during 3 days at $30^{\circ} \mathrm{C}$ and stored at $4{ }^{\circ} \mathrm{C}$. The cells suspension was grown during $24 \mathrm{~h}$ at $30^{\circ} \mathrm{C}$ and $150 \mathrm{rpm}$. Cells concentration was determined using an improved Neubauer chamber, and afterwards adjusted to an optical density of 1.0, measured at $620 \mathrm{~nm}$ in a Synergy HT Multi-Mode Microplate Reader (Bio-Tek Instruments, USA), corresponding to $6.5 \times 10^{7}$ cells $\mathrm{mL}^{-1}$.

\subsection{Shake-flask experiments}

Shake-flasks of $250 \mathrm{~mL}$ covered with aluminum caps were used. Assays run before the culture media and operational conditions optimization were performed with $45 \mathrm{~mL}$ of the following fermentation medium: $5.0 \mathrm{~g} \mathrm{~L}^{-1}$ yeast extract, $5.0 \mathrm{~g} \mathrm{~L}^{-1} \mathrm{NaNO}_{3}, 4.0 \mathrm{~g} \mathrm{~L}^{-1} \mathrm{KH}_{2} \mathrm{PO}_{4}$, $0.5 \mathrm{~g} \mathrm{~L}^{-1} \mathrm{KCl}, 0.35 \mathrm{~g} \mathrm{~L}^{-1} \mathrm{~K}_{2} \mathrm{SO}_{4}, 0.5 \mathrm{~g} \mathrm{~L}^{-1} \mathrm{MgSO}_{4} .7 \mathrm{H}_{2} \mathrm{O}$ and $0.01 \mathrm{~g} \mathrm{~L}^{-1}$ $\mathrm{FeSO}_{4} .7 \mathrm{H}_{2} \mathrm{O}$ and $200 \mathrm{~g} \mathrm{~L}^{-1}$ sucrose. Sucrose and $\mathrm{FeSO}_{4} .7 \mathrm{H}_{2} \mathrm{O}$ solutions were sterilized by filtration $(0.2 \mu \mathrm{m})$ and the other salt solutions were autoclaved at $121^{\circ} \mathrm{C}$ for $15 \mathrm{~min}$. The $\mathrm{pH}$ of the culture medium was adjusted to 6.2 before inoculation and assays were run at $30^{\circ} \mathrm{C}$ and 150 rpm (Nobre et al., 2016; Nobre, Alves Filho et al., 2018).

A mono-culture fermentation was run with A. ibericus under the abovementioned conditions. Shake-flasks were inoculated with $1 \mathrm{~mL}$ of A. ibericus spore suspension solution $\left(1 \times 10^{8}\right.$ spores per $\left.\mathrm{mL}\right)$. Co-culture fermentations were further conducted with both $A$. ibericus and $S$. cerevisiae YIL162 W strains. S. cerevisiae YIL162 W was inoculated with an optical density of 1.0 , corresponding to $6.5 \times 10^{7}$ cells per mL. Inoculation conditions were firstly optimized as following a) two inoculation volumes tested, namely 1 and $3 \mathrm{~mL}$; b) three inoculation times of the $S$. cerevisiae YIL162 W culture evaluated, namely at 0,10 and $20 \mathrm{~h}$ of the $A$. ibericus fermentation.

Samples were taken at different fermentation time points for further determination of sugar concentration.

\subsection{Experimental design and data analysis}

The fermentation broth composition from co-culture fermentations was optimized by experimental design to achieve maximal FOS purity. Additionally, the influence of $\mathrm{pH}$ and temperature conditions was also optimized.

The FOS purity was calculated according to the following equation:

FOS purity $(\%)=\frac{m_{F O S}}{m_{\text {total sugars }}} x 100$

where $m_{F O S}$ represents the sum of the individual mass of FOS (kestose $\mathrm{GF}_{2}$, nystose $-\mathrm{GF}_{3}$ and fructofuranosylnystose $-\mathrm{GF}_{4}$ ) and $m_{\text {total sugars }}$ represents the sum of the total mass of sugars (FOS, sucrose, fructose and glucose).

An initial $2^{3}$ central composite design (CCD), with three central points, was used for fermentation broth composition optimization, in which the three independent variables, $\mathrm{NaNO}_{3}, \mathrm{KH}_{2} \mathrm{PO}_{4}$ and yeast extract concentrations, were coded to dimensionless ones $\mathrm{X}_{1}, \mathrm{X}_{2}$ and $\mathrm{X}_{3}$, respectively, accordingly to the following equation:

$x_{i}=\frac{\left(X_{i}-X_{0}\right)}{\Delta X_{i}}, i=1,2, \ldots, k$

where $x_{\mathrm{i}}$ is the coded value of the independent variable, $\mathrm{X}_{\mathrm{i}}$ is the real value of an independent variable, $X_{0}$ is the real value of an independent variable at the central point and $\Delta \mathrm{X}_{\mathrm{i}}$ is the step change value.

Afterwards, for the operational conditions optimization, a $2^{2}$ CCD, with three central points, was used, in which two independent variables, temperature and $\mathrm{pH}$, were converted to dimensionless ones $\mathrm{X}_{4}$, and $\mathrm{X}_{5}$, respectively, accordingly to Eq. (2).

The medium component concentrations and operational conditions levels were established according to our previous work on FOS production maximization (Nobre et al., 2016; Nobre, Alves Filho et al., 2018). The range and levels of the independent variables studied is given in Table 1.

Experimental results were fitted with a second-order polynomial equation by multiple regression analysis (Eq. (3)). The quadratic mode for predicting the maximal FOS purity point based on the coded values of the independent variables $\left(\mathrm{X}_{\mathrm{i}}\right)$, were expressed according to the following equation:

FOS purity $(\%)=\beta_{0}+\sum_{i=1}^{k} \beta_{i} X_{i}+\sum_{i=1}^{k} \beta_{i i} X_{i}^{2}+\sum_{i=1}^{k-1} \sum_{j=i+1}^{k} \beta_{i j} X_{i} X_{j}$

where $\beta_{0}$ is the interception coefficient; $\beta_{i}, \beta_{i i}$ and $\beta_{i j}$ are the linear, squared and the cross-product coefficients, respectively; $k$ is the number of factors.

The Statistica 10.0 software (Statsoft, USA) was used for the experimental design and regression analysis of the experimental data. The effects of linear, quadratic and interactive terms of the independent variables on the chosen dependent variables were evaluated by the model. The quality of the fitted polynomial model was statistically

Table 1

Experimental range and levels of the independent variables selected for the two designs, according to the central composite design (CCD).

\begin{tabular}{llllll}
\hline & Independent variables & \multirow{2}{*}{ Symbol } & \multicolumn{2}{l}{ Range and levels } \\
\cline { 3 - 5 } & & & -1 & 0 & +1 \\
\hline \multirow{2}{*}{ Design 1 } & $\mathrm{NaNO}_{3}\left(\mathrm{~g} \mathrm{~L}^{-1}\right)$ & $\mathrm{X}_{1}$ & 5.0 & 10.0 & 15.0 \\
& $\mathrm{KH}_{2} \mathrm{PO}_{4}\left(\mathrm{~g} \mathrm{~L}^{-1}\right)$ & $\mathrm{X}_{2}$ & 4.0 & 6.0 & 8.0 \\
& Yeast Extract $\left(\mathrm{g} \mathrm{L}^{-1}\right)$ & $\mathrm{X}_{3}$ & 5.0 & 12.5 & 20.0 \\
Design 2 & $\mathrm{T}\left({ }^{\circ} \mathrm{C}\right)$ & $\mathrm{X}_{4}$ & 28.0 & 32.0 & 37.0 \\
& $\mathrm{pH}$ & $\mathrm{X}_{5}$ & 5.0 & 6.0 & 7.0 \\
\hline
\end{tabular}


checked by the magnitude of the coefficient of determination $R^{2}$ and its statistical significance was checked by the $F$-test analysis of variance (ANOVA). The coefficients of the response surface were evaluated using the student $t$-test.

Data were compared using one-way ANOVA followed by a Tukey's multiple comparison test with 95\% confidence level. Positive effects were considered significant for $p$-values lower than 0.05 .

\subsection{Bioreactor fermentation}

The inoculum of $A$. ibericus was prepared in a $250 \mathrm{~mL}$ flask, containing $100 \mathrm{~mL}$ of fermentation medium composed of $100 \mathrm{~g} \mathrm{~L}^{-1}$ sucrose and the optimized salt concentration. The inoculum medium was then seeded with $1 \mathrm{~mL}$ of the spore suspension solution $\left(1 \times 10^{8}\right.$ spores per $\mathrm{mL}$ ) and grown for 5 days at $30^{\circ} \mathrm{C}$ and $150 \mathrm{rpm}$. S. cerevisiae YIL162 W was grown in $150 \mathrm{~mL}$ of YPD, for 2 days, at $30^{\circ} \mathrm{C}$ and $150 \mathrm{rpm}$ of agitation. The optical density of the inoculum was then adjusted to 1.0 $\left(6.5 \times 10^{7}\right.$ cells per $\left.\mathrm{mL}\right)$ before addition to the bioreactor. An inoculum of $300 \mathrm{~mL}$ of the $S$. cerevisiae YIL162 W was used.

Fermentations were carried out in a $3.75 \mathrm{~L}$ bioreactor (Autoclavable Benchtop Fermenter Type R'ALF, Bioengineering AG, Switzerland). A working volume of $1 \mathrm{~L}$ of medium was used, containing $200 \mathrm{~g} \mathrm{~L}^{-1} \mathrm{su}^{-}$ crose and the previously optimized salt concentrations. The salts and yeast extract solutions were sterilized at $121^{\circ} \mathrm{C}$ for $30 \mathrm{~min}$, while sucrose and $\mathrm{FeSO}_{4} \cdot 7 \mathrm{H}_{2} \mathrm{O}$ were sterilized by filtration $(0.2 \mu \mathrm{m})$. All solutions were further added to the bioreactor under sterile conditions. Fermentations were conducted at $200 \mathrm{rpm}$ under the operational conditions optimized by experimental design. The $\mathrm{pH}$ was controlled using ortho-phosphoric acid and ammonium hydroxide solutions. First fermentations were performed without supplementation of air and the last ones were supplied with a constant aeration rate of $0.8 \mathrm{vvm}$ (selected based in experimental data obtained from fermentations previously conducted in the same bioreactor (data not shown)). Samples were collected during the fermentation for sugar concentration determination.

\subsection{Sugars and ethanol analysis}

Samples were analyzed by high-performance liquid chromatography (HPLC) for sugars and ethanol quantification. A HPLC (Jasco), equipped with a refractive index detector and a Prevail Carbohydrate ES column $(5 \mu \mathrm{m}, 25 \mathrm{~cm} \times 0.46 \mathrm{~cm}$ length $\times$ diameter) (Alltech), was used. Samples were eluted with a mixture of acetonitrile in pure-water (70:30, v/v) and $0.04 \%$ of ammonium hydroxide in water (HPLC Grade, Sigma-Aldrich, Germany). The elution was conducted at a flow rate of $1 \mathrm{~mL} \cdot \mathrm{min}^{-1}$ and $30^{\circ} \mathrm{C}$ (Nobre et al., 2016). The chromatographic signal was recorded and further integrated using the Star Chromatography Workstation software (Varian, USA). FOS standards were acquired from Wako (Japan). Sucrose, fructose and ethanol standards were obtained from Merck and glucose from VWR (Belgium).

\section{Results and discussion}

\subsection{FOS production by A. ibericus in mono-culture using shake-flasks}

The combination of two microorganisms as a co-culture to increase the purity of the FOS mixture was proposed. Primarily, the fermentation profile of $A$. ibericus MUM 03.49 was studied to confirm its ability to produce FOS (Fig. 1(a) and (b)). A maximum fermentation yield of $0.652 \pm 0.005 \mathrm{~g}_{\text {FOs }} \cdot \mathrm{g}_{\text {initial GF }}{ }^{-1}$ was obtained after $24 \mathrm{~h}$ of fermentation. A correspondent FOS concentration of $129.6 \pm 2.4 \mathrm{~g} \mathrm{~L}^{-1}$ was obtained at this time point, where $\mathrm{GF}_{2}, \mathrm{GF}_{3}$ and $\mathrm{GF}_{4}$ concentrations were, respectively, $78.3 \pm 4.7,49.3 \pm 3.1$ and $1.9 \pm 0.4 \mathrm{gL}^{-1}$. After this time point, $\mathrm{GF}_{2}$ was gradually converted into $\mathrm{GF}_{3}$, and further the $\mathrm{GF}_{3}$ was transformed into $\mathrm{GF}_{4}$ through transfructosylation reactions. Also, a decrease of the total FOS concentration and an increase of the fructose and glucose amounts in the medium was verified due to FOS hydrolysis.

During the first $10 \mathrm{~h}$ of fermentation, $A$. ibericus was adapting to the medium. Then, sucrose was quickly converted to FOS in a considerable rate until a maximal FOS concentration was reached $(24 \mathrm{~h})$. After this point, sucrose was consumed in a very slow rate due to the presence of high inhibitory amounts of glucose in the medium. At $60 \mathrm{~h}$ fermentation there was still $7.9 \pm 0.4 \mathrm{~g} \mathrm{~L}^{-1}$ of unreacted sucrose and an amount of $86.7 \pm 3.0 \mathrm{~g} \mathrm{~L}^{-1}$ of glucose. The glucose amount in the fermentation broth at the optimum point represented $26.2 \%$ of total sugars and the concentration of small sugars mixture in the medium was $85.1 \pm 2.0 \mathrm{~g} \mathrm{~L}^{-1}$. Thus, FOS were obtained with a purity of $60.4 \pm 0.4 \%(\mathrm{w} / \mathrm{w})$ and the productivity of the process was $5.4 \pm 0.1 \mathrm{~g}_{\mathrm{FOS}} \mathrm{L}^{-1} \mathrm{~h}^{-1}$.

\subsection{FOS production optimization}

In this work, FOS were synthesised through transfructosylation of sucrose by the $\beta$-fructofuranosidase and $\beta$-fructotransferase enzymes produced by the $A$. iberius. In the $A$. iberius fermentation, a $S$. cerevisiae strain was co-cultured to remove the high amount of glucose released during the FOS production.

The $S$. cerevisiae genome contains seven unlinked loci that encode invertase. This enzyme, also known as $\beta$-fructofuranosidase or "sucrase" plays an important role in the sugar metabolism. Invertase catalyses the hydrolysis of the disaccharide sucrose producing the monosaccharides fructose and glucose. Although individual S. cerevisiae strains may carry a number and combination of SUC genes, the reference strain herein used encodes only for the SUC2 gene (Saccharomyces genome database www.yeastgenome.org). To avoid competition by the substrate (sucrose), a strain of $S$. cerevisiae with SUC2 gene deleted was used, namely the $S$. cerevisiae YIL162 W.

Since $S$. cerevisiae YIL162 W showed potential to increase FOS purity without competing with $A$. ibericus by the substrate, and subsequently increasing the amount of FOS produced, this strain was used in the following experiments (Supplementary material).

\subsubsection{Optimization of the inoculum conditions}

After demonstrating the potential of $S$. cerevisiae YIL162 W for purifying FOS by removing the monosaccharides from the mixture, without competition by the substrate, the co-culture with the $A$. ibericus was optimized. Firstly, the inoculated cell amount of $S$. cerevisiae YIL162W was selected, and secondly, the best time to inoculate the yeast in the ongoing A. ibericus fermentation was evaluated. Results obtained inoculating at the beginning of the $A$. ibericus fermentation an amount of 1 or 3 times more cells of $S$. cerevisiae YIL162 W, corresponding to an inoculation volume of 1 and $3 \mathrm{~mL}$, respectively, are gathered in Table 2.

According to the statistical analysis, the amount of yeast inoculated did not affect significantly neither the FOS concentration $\left(\sim 122.5 \mathrm{~g} \mathrm{~L}^{-1} ; p=0.756\right)$ nor the yield of production $(\sim 0.61$ $\left.\mathrm{g}_{\mathrm{FOS}} \mathrm{g}_{\text {initial } \mathrm{GF}}{ }^{-1} ; p=0.318\right)$. On the other hand, the increase of the amount of cells inoculated significantly increased the purity of FOS obtained (from $84.9 \pm 1.0$ to $90.8 \pm 0.2 \% ; p=0.048$ ), even if the time required to reach the optimal point was longer ( 52.5 to $68.5 \mathrm{~h}$ ).

These preliminary results showed an increased FOS purity using the co-culture strategy as compared to the mono-culture ( $p<0.0003)$, in which FOS were produced with a purity of $60.4 \pm 0.4 \%(\mathrm{w} / \mathrm{w})$. Regarding the time to achieve the maximum FOS concentration, it was found that the presence of the yeast seems to delay the fermentation as compared to the mono-culture experiments (optimum time was $24 \mathrm{~h}$ ). On the other hand, the FOS concentration did not vary significantly between assays conducted by mono- or co-culture $(p>0.062)$, neither the yield while inoculating $3 \mathrm{~mL}$ of $S$. cerevisiae YIL162 W ( $p=0.068$ ). When inoculating $1 \mathrm{~mL}$ of the yeast, the yield was statistically lower $(p=0.014)$ as compared to assays in mono-culture. Since the aim of this study was to maximize the FOS purity, the inoculation of $3 \mathrm{~mL}$ of $S$. 


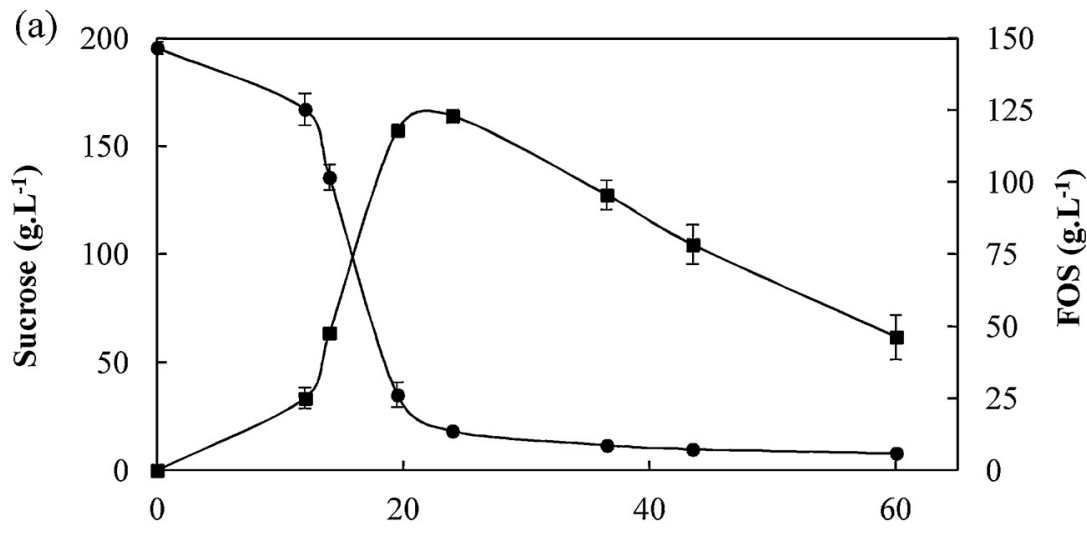

Fermentation time (h)

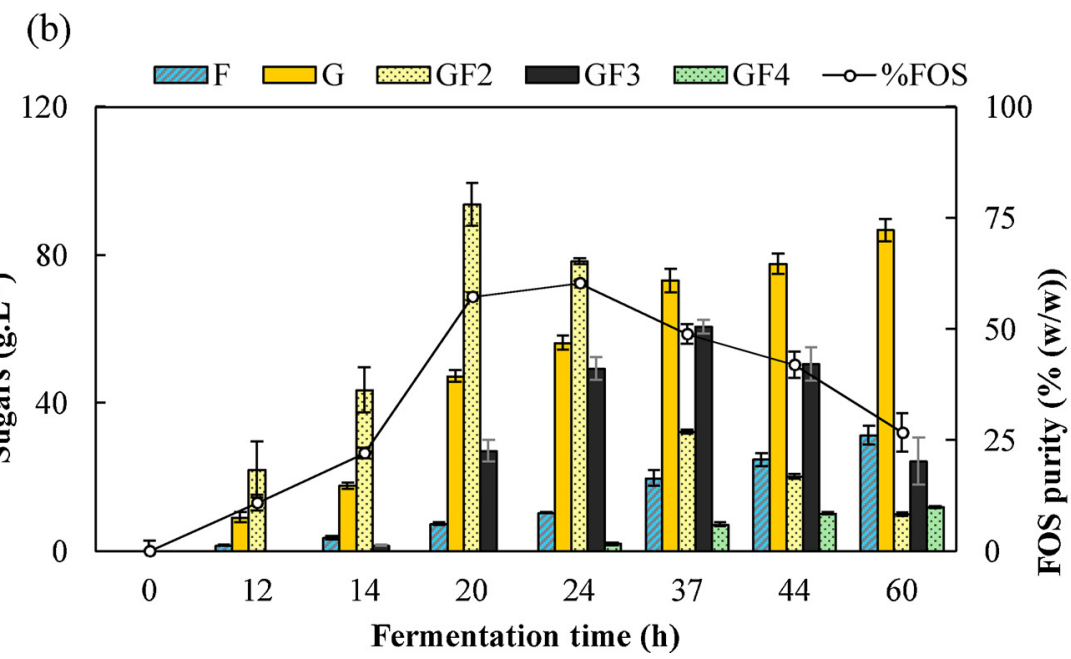

Fig. 1. Shake-flask fermentation profiles of Aspergillus ibericus: (a) sucrose (๑) and total fructo-oligosaccharides - FOS ( $\square$ ) concentration; (b) in primary axis, concentrations of: fructose - $\mathrm{F}$ (blue stripe bars), glucose - $\mathrm{G}$ (orange bars); kestose - $\mathrm{GF}_{2}$ (yellow dotted bars), nystose - $\mathrm{GF}_{3}$ (black bars) and fructofuranosylnystose $\mathrm{GF}_{4}$ (green dotted bars); in secondary axis: Purity of fructo-oligosaccharides - FOS $(O)$. The results correspond to the average \pm standard deviation of triplicate independent experiments. (For interpretation of the references to colour in this figure legend, the reader is referred to the web version of this article).

cerevisiae YIL162W in $45 \mathrm{~mL}$ of fermentation medium, at a $6.5 \times 10^{7}$ cells $\mathrm{mL}^{-1}$ concentration was selected for the following experiments to be conducted in shake-flasks.

Taking into account the fermentation profile obtained for the monoculture of $A$. ibericus, together with the profile obtained when $S$. cerevisiae YIL162W was inoculated simultaneously with $A$. ibericus, two additional times for the inoculation of the yeast were tested, namely $4.5 \mathrm{~h}$ and $16.5 \mathrm{~h}$. Results showed that the concentration of FOS $(p>$ $0.1)$ and yield $(p>0.09)$ were not statistically influenced by the time at which $S$. cerevisiae YIL162 W was inoculated. On the other hand, the purity of FOS significantly decreased when inoculating the yeast either at $4.5 \mathrm{~h}(p=0.04)$ or $16.5 \mathrm{~h}(p=0.001)$. Although productivity increased when the time of yeast inoculation was $16.5 \mathrm{~h}(p<0.01)$, the simultaneous inoculation of the fungi and $S$. cerevisiae YIL162 W was found to be the best strategy towards the production of FOS with a higher degree of purity.

A considerable decrease of glucose amount in the medium from $56.3 \pm 1.9$ to $2.1 \pm 0.9 \mathrm{~g} \mathrm{~L}^{-1}$ was observed. The amount of fructose was also reduced from $10.4 \pm 0.2$ to $2.4 \pm 0.4 \mathrm{~g} \mathrm{~L}^{-1}$. S. cerevisiae preference by glucose over fructose is well known as it is considered a glucophilic yeast (Guillaume, Delobel, Sablayrolles, \& Blondin, 2007). Consequently, although fructose is also expected to be consumed, the

Table 2

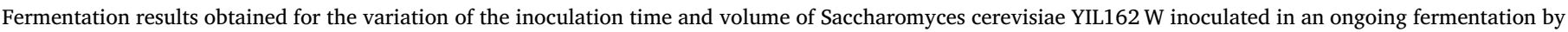

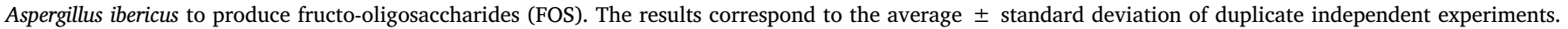

\begin{tabular}{|c|c|c|c|c|c|c|}
\hline Inoculation Time & Inoculation Volume $(\mathrm{mL})^{\mathrm{a}}$ & $\begin{array}{l}\text { Time } \\
\text { (h) }\end{array}$ & $\begin{array}{l}{[\mathrm{FOS}]} \\
\left(\mathrm{g} \mathrm{L}^{-1}\right)\end{array}$ & $\begin{array}{l}\text { FOS purity } \\
(\%(w / w))\end{array}$ & $\begin{array}{l}\text { Yield } \\
\left(g_{\text {FOs }} g_{\text {initial GF }}^{-1}\right)\end{array}$ & $\begin{array}{l}\text { Productivity } \\
\left(\mathrm{g}_{\mathrm{FOS}} \mathrm{L}^{-1} \mathrm{~h}^{-1}\right)\end{array}$ \\
\hline 0 & 1 & 52.5 & $123.0 \pm 4.0$ & $84.9 \pm 1.0$ & $0.59 \pm 0.02$ & $2.34 \pm 0.07$ \\
\hline 0 & 3 & 68.5 & $122.0 \pm 0.2$ & $90.8 \pm 0.2$ & $0.62 \pm 0.02$ & $1.78 \pm 0.00$ \\
\hline 4.5 & 3 & 45.0 & $115.3 \pm 1.7$ & $80.0 \pm 0.4$ & $0.56 \pm 0.08$ & $2.56 \pm 0.05$ \\
\hline 16.5 & 3 & 19.5 & $100 \pm 13$ & $53.2 \pm 3.8$ & $0.49 \pm 0.06$ & $5.16 \pm 0.67$ \\
\hline
\end{tabular}

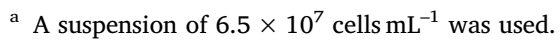


glucose is firstly exhausted from the medium. Hence, a discrepancy between the amount of glucose and fructose consumption during fermentation was expected.

A reduction of sucrose amount in the fermentation medium, at the optimal point, was also observed (from $18.4 \pm 0.7$ to $7.8 \pm 1.1 \mathrm{~g} \mathrm{~L}^{-1}$ ), thus meaning that the enzyme was more active in the hydrolysis and transfructosylation of the sucrose. This might be explained due to the glucose removal of the medium and consequent decrease of the enzyme inhibition by this sugar. Therefore, an increase of $\sim 30 \%$ in purity (from $60.4 \pm 0.4$ to $90.8 \pm 1.6 \%(\mathrm{w} / \mathrm{w}))$ was obtained. The concentration of $\mathrm{GF}_{2}, \mathrm{GF}_{3}$ and $\mathrm{GF}_{4}$ in the medium at the optimum point was $73.7 \pm 6.4,45.0 \pm 5.8$ and $3.4 \pm 0.8 \mathrm{~g} \mathrm{~L}^{-1}$, respectively. Compared to the FOS production by the mono-culture of $A$. ibericus, a slight increase of the $\mathrm{GF}_{4}$ and a reduction of the $\mathrm{GF}_{2}$ and $\mathrm{GF}_{3}$ concentrations was observed, although with no statistical significance, suggesting that the transfructosylation activity of the enzyme increased.

Based on these results, in the following assays, S. cerevisiae YIL162 W was always inoculated at the same time as A. ibericus.

\subsubsection{Optimization of the fermentative broth composition}

A first factorial design was performed to identify salts and yeast extract (YE) concentrations on the fermentation broth that lead to higher purity of FOS in the mixtures. Seventeen independent assays were performed at $30{ }^{\circ} \mathrm{C}\left(\mathrm{X}_{4}\right)$ and initial $\mathrm{pH} 6.2\left(\mathrm{X}_{5}\right)$. FOS purity determined on each assay is shown in Table 3.

Purity in FOS was higher than $70 \%$ for all the conditions tested, meaning that the co-culture improved the purity in FOS, as compared to the mono-culture $(60.4 \pm 0.4 \%(\mathrm{w} / \mathrm{w}))$, independently on the fermentation broth composition tested. Nevertheless, several assays obtained purities higher than $91 \%(\mathrm{w} / \mathrm{w})$. The highest purity was obtained when the co-culture was cultivated in a fermentation broth with the lowest concentration of $\mathrm{NaNO}_{3}\left(5 \mathrm{~g} \mathrm{~L}^{-1}\right)$ and average concentration of both $\mathrm{KH}_{2} \mathrm{PO}_{4}\left(6 \mathrm{gL}^{-1}\right)$ and $\mathrm{YE}\left(12.5 \mathrm{~g} \mathrm{~L}^{-1}\right)$.

Given the differences observed in the results, a statistical analysis was carried out aiming at identifying which independent variable significantly influences the purity of FOS. The statistical significance of $\mathrm{NaNO}_{3}, \mathrm{KH}_{2} \mathrm{PO}_{4}$ and YE on the purity of FOS is given in Table 4. Neither the concentration of $\mathrm{NaNO}_{3}$ nor $\mathrm{KH}_{2} \mathrm{PO}_{4}$ affected significantly the FOS percentage in the range of concentrations tested given that $p>>0.05$. On the other hand, the YE concentration presents a statistically

Table 3

Experimental runs using coded levels of $\mathrm{NaNO}_{3}, \mathrm{KH}_{2} \mathrm{PO}_{4}$ and yeast extract according to the $2^{3}$ central composite design (CCD) and FOS percentage obtained under those conditions.

\begin{tabular}{|c|c|c|c|c|c|c|}
\hline \multirow[t]{2}{*}{ Runs } & \multicolumn{3}{|c|}{ Independent Variables } & \multicolumn{2}{|c|}{ FOS purity $(\%(w / w))$} & \multirow[b]{2}{*}{ Residues } \\
\hline & $\mathrm{X}_{1}$ & $\mathrm{X}_{2}$ & $\mathrm{X}_{3}$ & Experimental & Predicted & \\
\hline 1 & -1 & -1 & -1 & 72.86 & 74.50 & -1.64 \\
\hline 2 & -1 & -1 & +1 & 95.90 & 94.77 & 1.13 \\
\hline 3 & -1 & +1 & -1 & 72.32 & 72.43 & -0.11 \\
\hline 4 & -1 & +1 & +1 & 94.21 & 96.19 & -1.98 \\
\hline 5 & +1 & -1 & -1 & 78.91 & 77.37 & 1.54 \\
\hline 6 & +1 & -1 & +1 & 92.92 & 93.26 & -0.34 \\
\hline 7 & +1 & +1 & -1 & 71.08 & 72.66 & -1.57 \\
\hline 8 & +1 & +1 & +1 & 93.22 & 92.03 & 1.19 \\
\hline 9 & -1 & 0 & 0 & 97.23 & 94.62 & 2.61 \\
\hline 10 & +1 & 0 & 0 & 93.16 & 93.98 & -0.82 \\
\hline 11 & 0 & -1 & 0 & 94.50 & 95.19 & -0.69 \\
\hline 12 & 0 & +1 & 0 & 96.02 & 93.54 & 2.48 \\
\hline 13 & 0 & 0 & -1 & 78.48 & 76.70 & 1.78 \\
\hline 14 & 0 & 0 & +1 & 96.53 & 96.52 & 0.01 \\
\hline $15^{\mathrm{a}}$ & 0 & 0 & 0 & 94.38 & 95.56 & -1.18 \\
\hline $16^{\mathrm{a}}$ & 0 & 0 & 0 & 94.57 & 95.56 & -0.99 \\
\hline $17^{\mathrm{a}}$ & 0 & 0 & 0 & 94.15 & 95.56 & -1.41 \\
\hline
\end{tabular}

$\mathrm{X}_{1}, \mathrm{X}_{2}$ and $\mathrm{X}_{3}$ being the coded values of $\mathrm{NaNO}_{3}, \mathrm{KH}_{2} \mathrm{PO}_{4}$ and yeast extract, respectively.

${ }^{\text {a }}$ Central Points.
Table 4

Statistical analysis of the central composite design (CCD) performed for the optimization of the fermentative broth composition. The variables studied include $\mathrm{NaNO}_{3}, \mathrm{KH}_{2} \mathrm{PO}_{4}$ and yeast extract concentration (Design 1) and temperature and $\mathrm{pH}$ (Design 2). The response variable was FOS purity.

\begin{tabular}{lllllll}
\hline $\begin{array}{l}\text { Variables and } \\
\text { interactions }\end{array}$ & & & $\begin{array}{l}\text { Estimated } \\
\text { effects }\end{array}$ & $\begin{array}{l}\text { Standard } \\
\text { Errors }\end{array}$ & t-value & $p$-value \\
\cline { 1 - 3 } \cline { 5 - 6 } Design 1 & $\mathrm{X}_{1}$ & & -0.644 & 1.431 & -0.450 & 0.666 \\
& $\mathrm{X}_{1}{ }^{2}$ & & -2.522 & 2.765 & -0.912 & 0.392 \\
& $\mathrm{X}_{2}$ & -1.649 & 1.431 & -1.152 & 0.287 \\
& $\mathrm{X}_{2}{ }^{2}$ & -2.392 & 2.765 & -0.865 & 0.416 \\
& $\mathrm{X}_{3}$ & 19.823 & 1.431 & 13.850 & 0.000 \\
& $\mathrm{X}_{3}{ }^{2}$ & -17.903 & 2.765 & -6.475 & 0.000 \\
& $\mathrm{X}_{1} \mathrm{X}_{2}$ & -1.325 & 1.600 & -0.828 & 0.435 \\
& $\mathrm{X}_{1} \mathrm{X}_{3}$ & -2.193 & 1.600 & -1.370 & 0.213 \\
& $\mathrm{X}_{2} \mathrm{X}_{3}$ & 1.743 & 1.600 & 1.089 & 0.312 \\
Design 2 & $\mathrm{X}_{4}$ & -27.165 & 1.830 & -14.842 & 0.000 \\
& $\mathrm{X}_{4}{ }^{2}$ & -26.452 & 2.817 & -9.391 & 0.000 \\
& $\mathrm{X}_{5}$ & -1.186 & 1.830 & -0.648 & 0.546 \\
& $\mathrm{X}_{5}{ }^{2}$ & 4.328 & 2.817 & 1.537 & 0.185 \\
& $\mathrm{X}_{4} \mathrm{X}_{5}$ & -4.237 & 2.242 & -1.890 & 0.117 \\
\hline
\end{tabular}

$\mathrm{X}_{1}, \mathrm{X}_{2}, \mathrm{X}_{3}, \mathrm{X}_{4}$ and $\mathrm{X}_{5}$ are the coded values of $\mathrm{NaNO}_{3}, \mathrm{KH}_{2} \mathrm{PO}_{4}$, yeast extract concentration, Temperature and $\mathrm{pH}$, respectively.

* Significant influence at 95\% confidence level.

significant effect on the FOS purity. The positive effect of YE means that an increase of the YE concentration will lead to a higher FOS percentage. The interaction between the studied variables were not significant at a $95 \%$ confidence level.

The effect of the independent factors on FOS purity can be better visualized by examining the surface plot. The three-dimensional response surface curves (Fig. 2(a) and (b)) clearly show that the percentage of FOS was not significantly affected neither by $\mathrm{NaNO}_{3}$ nor $\mathrm{KH}_{2} \mathrm{PO}_{4}$, while for yeast extract, an optimum point was found after which higher or lower concentration values did not improve the FOS purity. Yeast extract is a source of nitrogen, soluble B vitamins, amino acids and co-factors, which are essential for the growth of various microorganisms.

Experimental values were further fitted to a second order equation obtained by multiple regression analysis (Eq. (3)). Both F-test and ANOVA analysis were used as significance criteria for the fitted model. The calculated $F$-value (31.49) was higher than the listed one $\left(F_{9.7}=3.68\right)$ thus, the model was considered statistically significant at 95\% confidence level. The model explained $97.6 \%$ of the dependent variable's variability $\left(R^{2}=0.976\right)$ with a good adjusted determination coefficient $\left(R_{\text {adjusted }}^{2}=0.945\right)$. Based on the $R^{2}$ value determined, the model was considered accurate leading to a good prediction performance.

The simplified model proposed after elimination of the statistically insignificant terms is given in Eq. (4):

FOS purity $(\%)=38.22+5.24[Y E]-0.16[Y E]^{2}$

The values predicted by the model are presented in Table 3 along with the values observed experimentally. The central composite design (CCD) and regression analysis were effective in identifying the optimal conditions that maximize the percentage of FOS as a good agreement between the predicted and the experimental values was found.

Within the range of concentrations studied, the following optimal concentration values were obtained by the model for FOS purity maximization: $8.2 \mathrm{~g} \mathrm{~L}^{-1}$ of $\mathrm{NaNO}_{3}, 5.9 \mathrm{~g} \mathrm{~L}^{-1}$ of $\mathrm{KH}_{2} \mathrm{PO}_{4}$ and $16.8 \mathrm{~g} \mathrm{~L}^{-1}$ of $\mathrm{YE}$. Under these conditions the model predicted a FOS purity of $98.4 \%$ (w/ w). In order to validate the fitted model, three independent fermentations were conducted under the optimized conditions in shake-flasks (Fig. 3).

A FOS purity of $97.4 \pm 0.2 \%(\mathrm{w} / \mathrm{w})$ was obtained after $68.5 \mathrm{~h}$, with a FOS content of $116.1 \pm 6.0 \mathrm{~g} \mathrm{~L}^{-1}$ and a FOS production yield of 

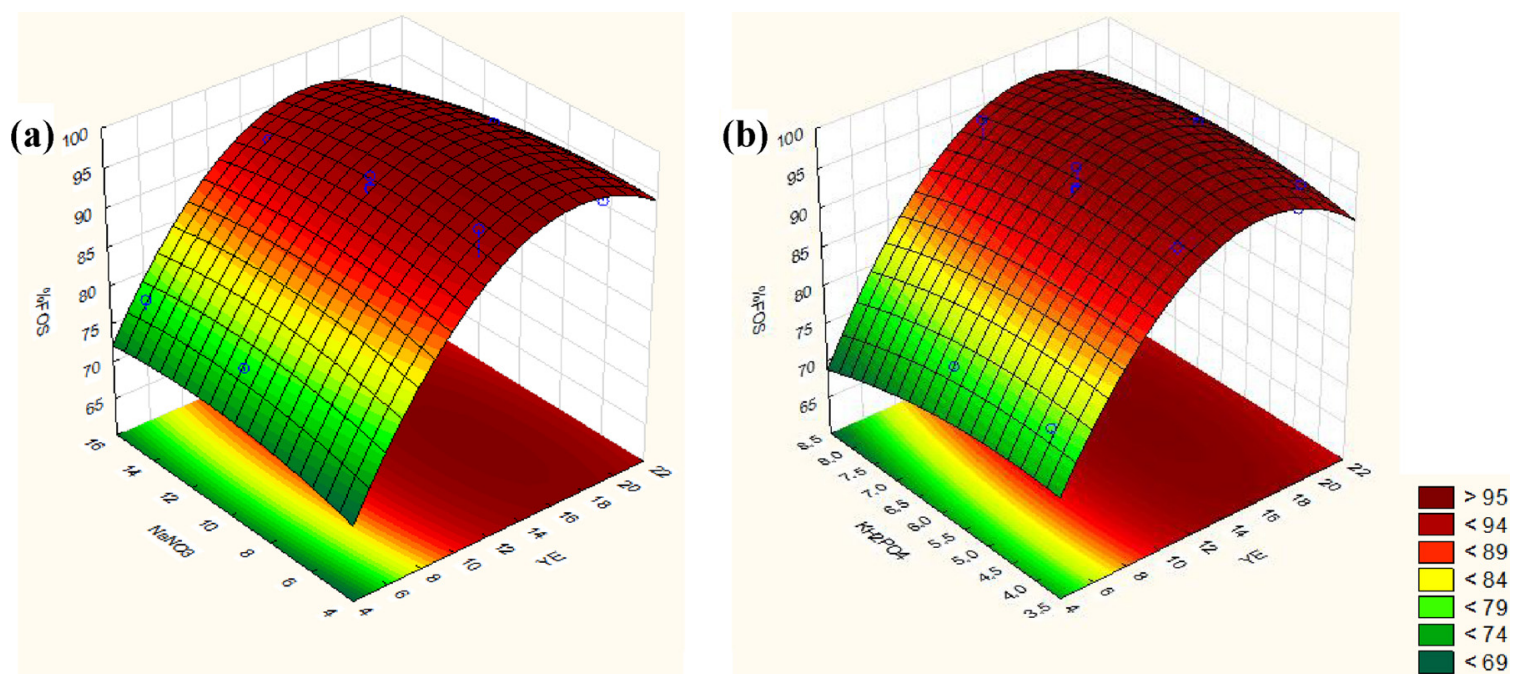

Fig. 2. Response surface of the central composite design (CCD) for the optimization of the fructo-oligosaccharides purity (\% FOS ( $w / w)$ ) as function of the NaNO ${ }_{3}$, $\mathrm{KH}_{2} \mathrm{PO}_{4}$ and yeast extract $(\mathrm{YE})$ concentration $\left(\mathrm{g} \mathrm{L}^{-1}\right)$ conditions.

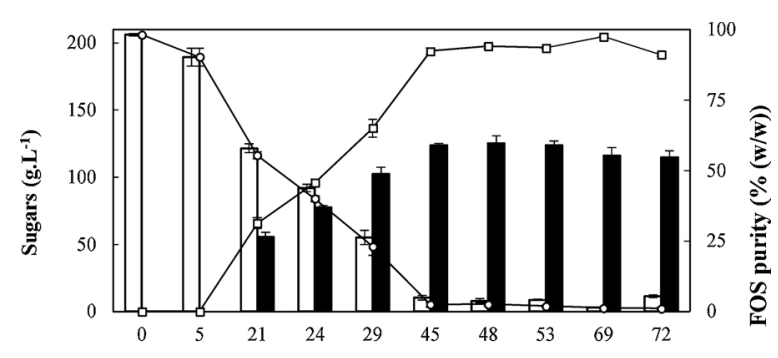

Fermentation time (h)

Fig. 3. Fermentation profile in shake-flasks under the optimized conditions (8.2 $\mathrm{g} \mathrm{L}^{-1}$ of $\mathrm{NaNO}_{3}, 5.9 \mathrm{~g} \mathrm{~L}^{-1}$ of $\mathrm{KH}_{2} \mathrm{PO}_{4}$ and $16.8 \mathrm{~g} \mathrm{~L}^{-1}$ of yeast extract). Small sugars concentration (white bars); total FOS concentration (black bars); sucrose concentration (O); Purity of fructo-oligosaccharides - FOS (\% (w/w)) ( $\square$ ); Sugars concentration in the primary axis and \% of FOS in the secondary axis. The results correspond to the average \pm standard deviation of triplicate independent experiments.

$0.56 \pm 0.03 \mathrm{~g}_{\mathrm{FOS}} \mathrm{g}_{\text {initial GF }}{ }^{-1}$. The concentration of fructose and glucose on the mixture at the optimum point were $0.23 \pm 0.06$ and $0.24 \pm 0.04 \mathrm{~g} \mathrm{~L}^{-1}$, respectively. Moreover, the amount of sucrose was only $2.6 \pm 0.3 \mathrm{~g} \mathrm{~L}^{-1}$. The FOS percentage found experimentally is in good agreement with the predicted one, confirming once more the significance of the model.

\subsubsection{Optimization of the operational fermentation conditions}

A second factorial design was assessed to evaluate the effect of temperature and $\mathrm{pH}$ variation on the purity of the FOS achieved. Eleven experiments were run using the broth composition optimized in the first design $\left(\mathrm{X}_{1}: 8.2 \mathrm{~g} \mathrm{~L}^{-1}\right.$ of $\mathrm{NaNO}_{3}, \mathrm{X}_{2}: 5.9 \mathrm{~g} \mathrm{~L}^{-1}$ of $\mathrm{KH}_{2} \mathrm{PO}_{4}$ and $\mathrm{X}_{3}$ : $16.8 \mathrm{~g} \mathrm{~L}^{-1}$ of YE) and the respective FOS purities obtained are shown in Table 5.

The experimental values were fitted on a second-order equation obtained by multiple regression analysis (Eq. (3)). The $\mathrm{F}$ test and ANOVA analysis showed that the model was statistically significant at $95 \%$ confidence level. The calculated $F$-value (62.69) was significantly higher than the listed one $\left(F_{5.5}=5.05\right)$. The coefficient of determination was also considerably high $\left(R^{2}=0.984\right)$ with a good adjusted determination coefficient $\left(R_{\text {adjusted }}^{2}=0.920\right.$ ) ensuring a good adjustment of the quadratic model. Given that, the FOS purities prediction of the proposed model was considered accurate in the studied experimental region.
Table 5

Experimental runs using coded levels of Temperature $\left(\mathrm{X}_{4}\right)$ and $\mathrm{pH}\left(\mathrm{X}_{5}\right)$ according to the $2^{2}$ central composite design (CCD) and FOS purity obtained under those conditions.

\begin{tabular}{lllllll}
\hline \multirow{2}{*}{ Runs } & \multicolumn{2}{l}{ Independent Variables } & & \multicolumn{2}{l}{ FOS purity $(\%(w / w))$} & \\
\cline { 2 - 3 } & $\mathrm{X}_{4}$ & $\mathrm{X}_{5}$ & & Experimental & Predicted & \multirow{2}{*}{ Residues } \\
\hline 1 & -1 & -1 & & 92.41 & 92.33 & 0.08 \\
2 & -1 & 0 & & 92.10 & 91.69 & 0.42 \\
3 & -1 & +1 & & 94.88 & 95.38 & -0.50 \\
4 & 0 & -1 & 92.11 & 94.09 & -1.98 \\
$5^{\text {a }}$ & 0 & 0 & 92.21 & 91.33 & 0.88 \\
$6^{\text {a }}$ & 0 & 0 & 93.22 & 91.33 & 1.89 \\
$7^{\text {a }}$ & 0 & 0 & 91.38 & 91.33 & 0.04 \\
8 & 0 & +1 & & 92.08 & 92.90 & -0.83 \\
9 & +1 & -1 & & 71.30 & 69.40 & 1.90 \\
10 & +1 & 0 & 61.30 & 64.52 & -3.22 \\
11 & +1 & +1 & 65.30 & 63.98 & 1.32 \\
\hline
\end{tabular}

a Central Points.

Table 5 shows the effect of $\mathrm{pH}$ and temperature on the purity of FOS achieved in the fermentation mixtures obtained at the optimal point. Based on the statistical analysis, in the range of the tested concentrations, only the temperature (both the linear and the quadratic terms) affected significantly the purity of FOS attained. The negative effect associated means that a decrease of the temperature will lead to higher FOS purity. Both $\mathrm{pH}$ and the interaction between the studied variables were not significant at a $95 \%$ confidence level.

The model equation attained, after elimination of the statistically insignificant terms is given in Eq. (5), where T represents the temperature:

FOS purity $(\%)=-363.36+33.69 T-0.53 T^{2}$

Predicted values by the model and the values experimentally observed were in good agreement, as shown in Table 5.

The optimal temperature found by the model to enhance FOS purity with the co-culture was $30^{\circ} \mathrm{C}$. A. ibericus MUM 03.49 is able to grow between $25-37^{\circ} \mathrm{C}$ with good FOS production above $30^{\circ} \mathrm{C}$ and maximal production at $37^{\circ} \mathrm{C}$ (Nobre, Alves Filho et al., 2018). The optimum grow conditions for the $S$. cerevisiae spp. used is between $25-30{ }^{\circ} \mathrm{C}$, as indicated by the strain source (EUROSCARF). Accordingly, $30^{\circ} \mathrm{C}$ is a good compromise to guarantee the growth of both species in co-culture.

The $\mathrm{pH}$ showed no significant influence on the purity of FOS achieved within the range studied. Thus, since maximal FOS production 


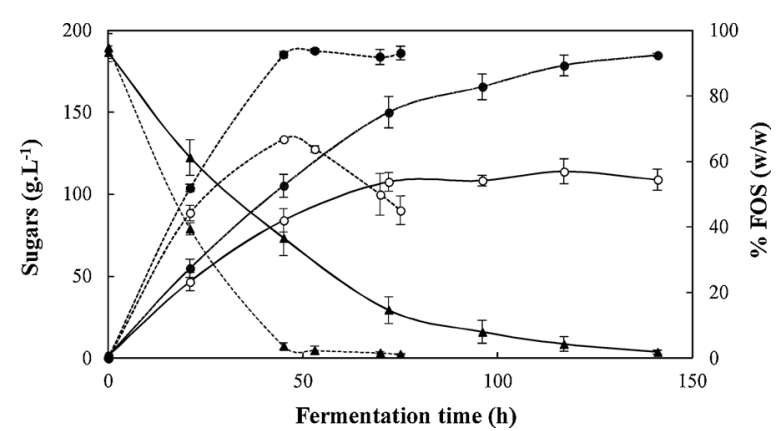

Fig. 4. Sugars profile obtained in fermentations run in bioreactor at $30{ }^{\circ} \mathrm{C}$ and $\mathrm{pH} 6.0$ with (solid line) and without aeration (dash line). Sucrose $(\boldsymbol{\Delta})$ and fructo-oligosaccharides - FOS $(O)$ concentration in the primary axis and FOS percentage (O) in the secondary axis. Results correspond to the average of three independent experiments \pm standard deviation.

with A. ibericus is obtained with a $\mathrm{pH}$ around 6.0, the following experiments run in the bioreactor were performed at this fixed $\mathrm{pH}$ (Nobre, Alves Filho et al., 2018).

\subsection{FOS production in bioreactor}

After the optimization of the fermentation culture medium and operational conditions in shake-flask, the fermentation was scaled-up to a $3.75 \mathrm{~L}$ bioreactor. A fermentation broth composed by $200 \mathrm{~g} \mathrm{~L}^{-1}$ sucrose, $0.5 \mathrm{~g} \mathrm{~L}^{-1} \mathrm{KCl}, 0.35 \mathrm{~g} \mathrm{~L}^{-1} \mathrm{~K}_{2} \mathrm{SO}_{4}, 0.5 \mathrm{~g} \mathrm{~L}^{-1} \mathrm{MgSO}_{4} \cdot 7 \mathrm{H}_{2} \mathrm{O}, 0.01 \mathrm{gL}^{-1}$ $\mathrm{FeSO}_{4} \cdot 7 \mathrm{H}_{2} \mathrm{O}, 8.0 \mathrm{~g} \mathrm{~L}^{-1} \mathrm{NaNO}_{3}, 6.0 \mathrm{~g} \mathrm{~L}^{-1} \mathrm{KH}_{2} \mathrm{PO}_{4}$ and $17.0 \mathrm{gL}^{-1} \mathrm{YE}$ was used, and the experiments were run under controlled temperature and $\mathrm{pH}$ of $30^{\circ} \mathrm{C}$ and 6.0 , respectively. Fig. 4 shows the concentration profile of the sucrose consumed and the respective FOS produced, as well as the purity of FOS obtained for the experiments run.

At first, assays were run without aeration since $A$. ibericus is able to produce good FOS yields without extra air supply when grown in monoculture under similar conditions, namely same bioreactor shape, agitation impellers and speed (Nobre, Alves Filho et al., 2018). Under these conditions, FOS purities of $92.5 \pm 0.5 \%$ were attained at $141 \mathrm{~h}$ fermentation. The concentration of FOS in the mixture was $108.9 \pm 6.6 \mathrm{~g} \mathrm{~L}^{-1}$, with $50.3 \pm 7.8 \quad \mathrm{GF}_{2}, 54.2 \pm 2.0 \quad \mathrm{GF}_{3}$ and $4.4 \pm 0.9 \mathrm{~g} \mathrm{~L}^{-1} \mathrm{GF}_{4}$. Small saccharides represented only $7.5 \%$ of the total sugars, in a concentration of $8.8 \pm 1.0 \mathrm{~g} \mathrm{~L}^{-1}$. A FOS fermentation yield of $0.59 \pm 0.03 \mathrm{~g}_{\mathrm{FOS}} \cdot \mathrm{g}_{\text {initial GF }}{ }^{-1}$ was obtained with a productivity of $0.77 \pm 0.04 \mathrm{~g}_{\mathrm{FOS}} \mathrm{L}^{-1} \cdot \mathrm{h}^{-1}$.

The maximum concentration of $\mathrm{GF}_{2}$ was obtained at $72 \mathrm{~h}$, with further conversion into $\mathrm{GF}_{3}$ and $\mathrm{GF}_{4}$ through the transfructosylation reaction. Maximum FOS concentration of $114.0 \pm 7.5 \mathrm{~g} \mathrm{~L}^{-1}$ was obtained earlier, at $117 \mathrm{~h}$, although with a slightly inferior purity of FOS of $89.3 \pm 2.2 \%$.

As compared to the assays run with the mono-culture, great purities of FOS were achieved since the monosaccharides decreased from $85.1 \pm 2.0 \mathrm{~g} \mathrm{~L}^{-1}$ to $8.8 \mathrm{~g} \mathrm{~L}^{-1} \pm 2.0 \mathrm{~g} \mathrm{~L}^{-1}$. Regarding the FOS produced, a $15 \mathrm{~g} \mathrm{~L}^{-1}$ decrease was found in the maximal amount obtained. On the other hand, the time needed to achieve maximal production was much higher when using the co-culture. The presence of the yeast seems to delay the fermentation, although the yeast is not competing by the substrate, which can be observed by the similar amount of FOS produced in mono- and co-culture. Consequently, the fermentation productivity also decreased substantially. The rate of sucrose consumption/conversion is less affected when using the $S$. cerevisiae BY4741 wild type as shown in Fig. S1. Accordingly, in a work conducted with a co-culture of $A$. pullulans and $S$. cerevisiae, the sucrose consumption profile obtained was very similar, as well the maximum FOS production time (Nobre et al., 2016).

Considering that Aspergillus species are mostly aerobic moulds (Hall \& Denning, 1994) and S. cerevisiae grow either in aerobic or anaerobic conditions, even if they cannot truly grow under strictly anaerobic conditions (Walker \& Stewart, 2016), an aeration of 0.8 vvm was supplied to the fermentation medium. The provided oxygen enhanced the strains growth and consequently, the sucrose conversion rate (Fig. 4). Most probably, when inoculating $S$. cerevisiae YIL162 W simultaneously with $A$. ibericus in the bioreactor, the oxygen transfer rate decreased to a critical value that inhibited the strains growth. In the shake-flasks experiments this effect was less evident since both agitation and headspace are different, resulting in fermentation times lower than $48 \mathrm{~h}$ to obtain maximal FOS production.

When introducing air in the bioreactor, the fermentation time required to reach maximal FOS production decreased noticeably from $117 \mathrm{~h}$ to $45 \mathrm{~h}$, which improved considerably the process productivity to $3.0 \pm 0.0 \mathrm{~g}_{\mathrm{FOS}} \mathrm{L}^{-1} \mathrm{~h}^{-1}$. Besides, the amount of FOS produced, as well as the fermentation yield, increased significantly to $133.7 \pm 0.1 \mathrm{~g} \mathrm{~L}^{-1}$ and $0.70 \pm 0.00 \mathrm{~g}_{\mathrm{FOS}} \mathrm{g}_{\text {initial } \mathrm{GF}^{-1}}$, respectively. $S$. cerevisiae YIL162W reduced the amount of monosaccharides to residual values of $1.1 \pm 0.4 \mathrm{~g} \mathrm{~L}^{-1}$ fructose and $2.2 \pm 0.9 \mathrm{gL}^{-1}$ glucose. The glucose amount reduction had an effective impact on the activity of the $\beta$ fructofuranosidase enzyme from the $A$. ibericus, thus raising the FOS fermentation yield to values even greater than the ones obtained in mono-culture. FOS fermentation yields herein obtained are noticeably higher than the ones reported for other microorganisms (Dominguez, Rodrigues, Lima, \& Teixeira, 2013; Ganaie, Lateef, \& Gupta, 2014; Mano et al., 2018). Moreover, since the microorganisms whole-cells are used as an alternative to the isolated enzymes, which is the methodology predominantly used by other reports, the overall process of FOS production is much faster (Sangeetha, Ramesh, \& Prapulla, 2005). The use of the whole-cells avoids the enzyme purification step, shorten the process from two-stages to one-stage.

The sugar mixtures collected achieved a maximal purity in FOS of $93.8 \pm 0.7 \%$ at $53 \mathrm{~h}$ fermentation. At $45 \mathrm{~h}$, fermentation mixtures contained $92.6 \% \pm 1.0 \%$ of pure FOS. The main small sugar in the mixture was sucrose with a concentration of $7.4 \pm 2.1$ and $4.9 \pm 2.6 \mathrm{~g} \mathrm{~L}^{-1}$ for 45 and $53 \mathrm{~h}$, respectively. Sucrose was still being converted to FOS and decreased to residual values after this fermentation time. However, FOS also began to be hydrolysed resulting in a decrease of the total FOS amount (Figs. 4 and 5).

Individual sugar profiles vary along the fermentation time (Fig. 5). Samples collected between 45 and $53 \mathrm{~h}$ were richer in $\mathrm{GF}_{2}$, while for 70 and $75 \mathrm{~h}$ the main sugar present was $\mathrm{GF}_{3}$. Since the purity of the mixture does not vary significantly during this time period $(92.8 \pm 0.8 \%)$, through the selection of a different harvesting fermentation time, a variety of mixtures containing different ratios of oligosaccharides may be obtained.

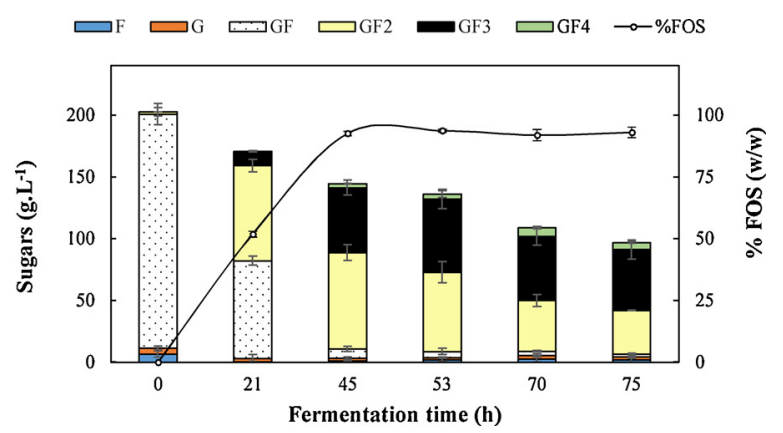

Fig. 5. Sugars profile obtained in fermentations run in bioreactor at $30{ }^{\circ} \mathrm{C}$ and pH 6.0 with aeration. In the primary axis concentrations of: fructose - F (blue bars), glucose - G (orange bars), sucrose - GF (dotted bars), kestose - $\mathrm{GF}_{2}$ (yellow bars), nystose - $\mathrm{GF}_{3}$ (black bars) and fructofuranosylnystose - $\mathrm{GF}_{4}$ (green bars); in the secondary axis: \% of fructo-oligosaccharides - FOS (O). Results correspond to the average of three independent assays \pm standard deviation. (For interpretation of the references to colour in this figure legend, the reader is referred to the web version of this article). 
An amount of $23.8 \pm 1.7 \mathrm{gL}^{-1}$ of ethanol was produced from glucose through $S$. cerevisiae YIL162W fermentation at the maximum FOS production time. The concentration of ethanol progressively increased after $75 \mathrm{~h}$ fermentation up to $35.5 \mathrm{~g} \mathrm{~L}^{-1} \pm 2.7 \mathrm{~g} \mathrm{~L}^{-1}$.

The integrated production and purification process using co-cultures was previously explored by our group using $A$. pullulans and $S$. cerevisae (Nobre et al., 2016). However, since the yeast strain did not have the SUC2 gene disrupted, there was competition by the substrate leading to lower fermentation yields and the purity only increased up to $58 \%$.

Sheu et al. (2002) used a cell system consisting in mycelia of $A$. japonicus or A. pullulans with a living Gluconobacter oxydans. The system worked in continuous mode for 7 days, using a microfiltration module to discharge the FOS produced. Although more than $80 \%$ of the sugars achieved were FOS, still $5-7 \%$ glucose and $8-10 \%$ sucrose on a dry weight basis remained in the harvested mixtures (Sheu et al., 2002).

In another cell system, consisting in A. japonicus and Pichia heimii cells immobilized in calcium alginate beads, FOS were produced in three-steps using three tanks-in-series run in continuous mode. In the first two tanks, FOS were produced by A. japonicus cells and purified by P. heimii cells to $70.2 \%$ (first tank) and $95.6 \%$ (second tank). The third tank was used just to increase the purity of FOS up to $98.2 \%$ by $P$. heimii. One gram of sucrose yielded $0.62 \mathrm{~g}$ of FOS (Sheu et al., 2013). Compared to the cell system, our work using the living free microorganisms instead of immobilized cells that worked as enzymes bags, yielded higher values of FOS $\left(0.70 \pm 0.00 \mathrm{~g}_{\mathrm{FOS}} \mathrm{g}_{\text {initial GF }}{ }^{-1}\right)$ and similar purities of the FOS produced were achieved $(93.8 \pm 0.7 \%)$ using only one tank reactor. Therefore, the results gathered showed that the integrated system herein proposed allows achieving high FOS content with great purities using a one-step bioprocess.

\section{Conclusions}

An integrated system allowing the simultaneous production and purification of FOS was explored. A co-culture of A. ibericus and $S$. cerevisiae YIL162 W showed to maximize the amount and purity of the FOS mixtures produced. Under optimized conditions a yield of $0.70 \pm 0.00 \mathrm{~g}_{\mathrm{FOS}} \mathrm{g}_{\text {initial GF }}{ }^{-1}$ was obtained at $45 \mathrm{~h}$ fermentation, with a content of $133.7 \pm 0.1 \mathrm{~g} \mathrm{~L}^{-1}$ in FOS. FOS mixtures with purities up to $93.8 \pm 0.7 \%$ were obtained.

In one single fermentation a high FOS content was produced, demonstrating that the system herein optimized is efficient, time-saving and economically attractive as compared to the conventional two-step bioprocess.

\section{Acknowledgements}

Clarisse Nobre and Lígia R. Rodrigues acknowledgethe Portuguese Foundation for Science and Technology (FCT) for the Grants reference SFRH/BPD/87498/2012 and SFRH/BSAB/142873/2018. This study was supported by the FCT under the scope of the strategic funding of UID/BIO/ 04469/2013 unit and COMPETE 2020 (POCI-01-0145-FEDER-006684) and BioTecNorte operation (NORTE-01-0145-FEDER-000004) funded by the European Regional Development Fund under the scope of Norte2020 Programa Operacional Regional do Norte also, Project ColOsH 02/SAICT/ 2017 (POCI-01-0145-FEDER-030071), MultiBiorefinery SAICTPAC/0040/ 2015 (POCI-01-0145-FEDER-016403), Biomass and Bioenergy Research Infrastructure 01/SAICT/2016 (PINFRA/22059/2016) and Project FoSynBio 02/SAICT/2017 (POCI-01-0145-FEDER-029549).

\section{Appendix A. Supplementary data}

Supplementary material related to this article can be found, in the online version, at doi:https://doi.org/10.1016/j.carbpol.2018.08.051.

\section{References}

Dominguez, A. L., Rodrigues, L. R., Lima, N. M., \& Teixeira, J. A. (2013). An overview of the recent developments on fructooligosaccharide production and applications. Food and Bioprocess Technology, 1-14.

Dominguez, A., Nobre, C., Rodrigues, L. R., Peres, A. M., Torres, D., Rocha, I., et al. (2012). New improved method for fructooligosaccharides production by Aureobasidium pullulans. Carbohydrate Polymers, 89(4), 1174-1179.

Ganaie, M. A., Lateef, A., \& Gupta, U. S. (2014). Enzymatic trends of fructooligosaccharides production by microorganisms. Applied Biochemistry and Biotechnology, 172(4), 2143-2159.

Guillaume, C., Delobel, P., Sablayrolles, J.-M., \& Blondin, B. (2007). Molecular basis of fructose utilization by the wine yeast Saccharomyces cerevisiae: A mutated HXT3 allele enhances fructose fermentation. Applied and Environmental Microbiology, 73(8), 2432-2439.

Hall, L. A., \& Denning, D. W. (1994). Oxygen requirements of Aspergillus species. Journal of Medical Microbiology, 41(5), 311-315.

Jung, K. H., Kim, J. H., Jeon, Y. J., \& Lee, J. H. (1993). Production of high fructo-oligosaccharide syrup with two enzyme system of fructosyltransferase and glucose oxidase. Biotechnology Letters, 15(1), 65-70.

Maiorano, A. E., Piccoli, R. M., Da Silva, E. S., \& De Andrade Rodrigues, M. F. (2008). Microbial production of fructosyltransferases for synthesis of pre-biotics. Biotechnology Letters, 30(11), 1867-1877.

Mano, M. C. R., Neri-Numa, I. A., da Silva, J. B., Paulino, B. N., Pessoa, M. G., \& Pastore, G. M. (2018). Oligosaccharide biotechnology: an approach of prebiotic revolution on the industry. Applied Microbiology and Biotechnology, 102(1), 17-37.

Mouelhi, R., Abidi, F., \& Marzouki, M. N. (2016). An improved method for the production of fructooligosaccharides by immobilized $\beta$-fructofuranosidase from Sclerotinia sclerotiorum. Biotechnology and Applied Biochemistry, 63(2), 281-291.

Nascimento, A. K. C., Nobre, C., Cavalcanti, M. T. H., Teixeira, J. A., \& Porto, A. L. F. (2016). Screening of fungi from the genus Penicillium for production of $\beta$ - fructofuranosidase and enzymatic synthesis of fructooligosaccharides. Journal of Molecular Catalysis B: Enzymatic, 134, 70-78.

Nishizawa, K., Nakajima, M., \& Nabetani, H. (2001). Kinetic study on transfructosylation by $\beta$-fructofuranosidase from Aspergillus niger ATCC 20611 and availability of a membrane reactor for fructooligosaccharide production. Food Science and Technology Research, 7(1), 39-44.

Nobre, C., Castro, C. C., Hantson, A.-L., Teixeira, J. A., De Weireld, G., \& Rodrigues, L. R. (2016). Strategies for the production of high-content fructo-oligosaccharides through the removal of small saccharides by co-culture or successive fermentation with yeast. Carbohydrate Polymers, 136, 274-281.

Nobre, C., Suvarov, P., \& De Weireld, G. (2014). Evaluation of commercial resins for fructo-oligosaccharide separation. New Biotechnology, 31(1), 55-63.

Nobre, C., Teixeira, J. A., \& Rodrigues, L. R. (2012). Fructo-oligosaccharides purification from a fermentative broth using an activated charcoal column. New Biotechnology, 29(3), 395-401.

Nobre, C., Alves Filho, E. G., Fernandes, F. A. N., Brito, E. S., Rodrigues, S., Teixeira, J. A., et al. (2018). Production of fructo-oligosaccharides by Aspergillus ibericus and their chemical characterization. LWT- Food Science and Technology, 89, 58-64.

Nobre, C., Cerqueira, M.Â., Rodrigues, L. R., Vicente, A. A., \& Teixeira, J. A. (2015) Chapter 19 - Production and extraction of polysaccharides and oligosaccharides and their use as new food additives. Industrial biorefineries \& white biotechnology. Elsevier B.V. pp. 653-679.

Nobre, C., Sousa, S. C., Silva, S. P., Pinheiro, A. C., Coelho, E., Vicente, A. A., et al. (2018) In vitro digestibility and fermentability of fructo-oligosaccharides produced by Aspergillus ibericus. Journal of Functional Foods, 46, 278-286.

Nobre, C., Teixeira, J. A., \& Rodrigues, L. R. (2015). New trends and technological challenges in the industrial production and purification of fructo-oligosaccharides. Critical Reviews in Food Science and Nutrition, 55(10), 1444-1455.

Sangeetha, P. T., Ramesh, M. N., \& Prapulla, S. G. (2005a). Fructooligosaccharide production using fructosyl transferase obtained from recycling culture of Aspergillus or yzae CFR 202. Process Biochemistry, 40(3-4), 1085-1088.

Sangeetha, P. T., Ramesh, M. N., \& Prapulla, S. G. (2005b). Maximization of fructooligosaccharide production by two stage continuous process and its scale up. Journal of Food Engineering, 68(1), 57-64.

Sheu, D.-C., Duan, K.-J., Cheng, C.-Y., Bi, J.-L., \& Chen, J.-Y. (2002). Continuous production of high-content fructooligosaccharides by a complex cell system. Biotechnology Progress, 18(6), 1282-1286.

Sheu, D. C., Chang, J. Y., Wang, C. Y., Wu, C. T., \& Huang, C. J. (2013). Continuous production of high-purity fructooligosaccharides and ethanol by immobilized Aspergillus japonicus and Pichia heimii. Bioprocess and Biosystems Engineering, 36(11), $1745-1751$.

Sheu, D. C., Lio, P. J., Chen, S. T., Lin, C. T., \& Duan, K. J. (2001). Production of fructooligosaccharides in high yield using a mixed enzyme system of $\beta$-fructofuranosidase and glucose oxidase. Biotechnology Letters, 23(18), 1499-1503.

Suvarov, P., Kienle, A., Nobre, C., De Weireld, G., \& Vande Wouwer, A. (2014). Cycle to cycle adaptive control of simulated moving bed chromatographic separation processes. Journal of Process Control, 24(2), 357-367.

Walker, G., \& Stewart, G. (2016). Saccharomyces cerevisiae in the production of fermented beverages. Beverages, 2(4), 30.

Yang, Y., Wang, J., Teng, D., \& Zhang, F. (2008). Preparation of high-purity fructo-oligosaccharides by Aspergillus japonicus $\beta$-fructofuranosidase and successive cultivation with yeast. Journal of Agricultural and Food Chemistry, 56(8), 2805-2809.

Younis, K., Ahmad, S., \& Jahan, K. (2015). Health benefits and application of prebiotics in foods. Journal of Food Processing \& Technology, 6(4), 1-7.

Yun, J. W., \& Song, S. K. (1993). The production of high-content fructo-oligosaccharides from sucrose by the mixed-enzyme system of fructosyltransferase and glucose oxidase. Biotechnology Letters, 15(6), 573-576. 